\title{
Cone-beam computed tomography in the assessment of periapical lesions in endodontically treated teeth
}

\author{
Gianluca Gambarini ${ }^{1}$, Lucila Piasecki ${ }^{2}$, Gabriele Miccoli ${ }^{1}$, Gianfranco Gaimari ${ }^{1}$, \\ Dario Di Nardo ${ }^{1}$, Luca Testarelli ${ }^{1}$
}

Correspondence: Dr. Dario Di Nardo, Email: dario.dinardo@uniroma1.it

\author{
'Department of Oral and Maxillofacial Sciences, \\ Sapienza University of Rome, Italy, \\ ${ }^{2}$ Department of Periodontics and Endodontics, \\ University at Buffalo, New York, USA
}

\section{ABSTRACT}

Objective: This study aimed to evaluate the relationship between the quality of the coronal restoration and the root canal filling on the periapical status of endodontically treated teeth using CBCT. Materials and Methods: CBCT data were obtained from the records of patients who deny any dental treatment in the 2 years prior to the CBCT examination. CBCT images (90 kVp and $7 \mathrm{~mA}$, exposure time of $23 \mathrm{~s}$, and a voxel size of $0.2 \mathrm{~mm}$, with a field of view of $13 \mathrm{~cm} \times 13 \mathrm{~cm}$ ) of 1011 endodontically treated teeth were observed. A score was given to the quality of the root filling and the quality of the coronal restoration. Statistical Analysis Used: Data were statistically analyzed to correlate the periapical status with gender, dental group. and quality of endodontic treatment and restoration (Chi-square test with a significance level of $P<0.001$ ). Results: Absence of periapical periodontitis was found in $54.9 \%$ of the cases. The periapical outcome was not related to gender or dental group $(P>0.05)$. A statistically significant factor (Chi-square test, $P<0.0001)$ resulted when different qualities of sealing were compared. Conclusions: CBCT showed that high-quality root canal treatments followed by an adequate coronal sealing restoration avoid the presence of periapical periodontitis in time.

Key-words: Cone-beam computed tomography, endodontic treatment, periapical periodontitis, restorative

\section{INTRODUCTION}

In 1995, Ray and Trope evaluated the relationship between the quality of coronal restoration, root canal obturation, and the radiographic periapical status of endodontically treated teeth. They found a radiologic success rate of $61.07 \%$ and stated that the technical quality of the coronal restoration had a greater impact on the endodontic success (defined as the radiographic absence of periapical radiolucency)

\begin{tabular}{|l|l|}
\hline \multicolumn{2}{|c|}{ Access this article online } \\
\hline Quick Response Code: & \\
\hline
\end{tabular}

than the technical quality of the endodontic obturation. ${ }^{[1]}$

In literature, there is consensus on the importance of hermetic three-dimensional, apical and coronal seal to prevent bacterial reinfection of root canals after endodontic treatment. ${ }^{[2-6]}$ On the other hand,

This is an open access article distributed under the terms of the Creative Commons Attribution-NonCommercial-ShareAlike 3.0 License, which allows others to remix, tweak, and build upon the work non-commercially, as long as the author is credited and the new creations are licensed under the identical terms.

For reprints contact: reprints@medknow.com

How to cite this article: Gambarini G, Piasecki L, Miccoli G, Gaimari G, Di Nardo D, Testarelli L. Cone-beam computed tomography in the assessment of periapical lesions in endodontically treated teeth. Eur J Dent 2018;12:136-43.

DOI: 10.4103/ejd.ejd_320_17 
the statement about the quality of coronal sealing being more important than the root canal obturation is controversial and has been corroborated by some studies ${ }^{[7,8]}$ and not supported by others. ${ }^{[9-14]}$

The evaluations on endodontic success have been mainly performed by means of only periapical radiographs,,$_{1,10,12,14,15]}$ combined with clinical examination $^{[7,9,16]}$ and, more recently, it has been performed by means of cone-beam computed tomography (CBCT).$^{[4,17]}$ The use of CBCT technology overcome the two-dimensional limitation of the radiographic images and improved the accuracy in the detection of periapical lesions compared to other dental radiographic means. ${ }^{[18-23]}$

Clinical and histological studies have shown that CBCT enables the detection of apical periodontitis before they would be apparent on the conventional radiographs, presenting findings closer to the gold standard, which is the histologic evaluation. ${ }^{[18,24]}$ The detection of apical lesions in radiographs is adequate only when there is a significant mineral bone loss, due to the reduced size in early stages, anatomical noise, and poor irradiation geometry. ${ }^{[18,25,26]}$ This means that radiographs present a low predictive value to detect the periapical disease or confirm the health status, while CBCT minimizes the false diagnoses and provides superior validity and reliability. ${ }^{[18,24-26]}$ Therefore, it has been suggested that the assessment of the success of endodontic treatment derived from only a two-dimensional evaluation of periapical radiographs may be insufficient. . $22,26-28]^{2}$

The endodontic treatment ideally should be clean, disinfect, and seal all the root canals and their ramifications, aiming to prevent or cure the apical periodontitis. ${ }^{[2]}$ However, even the most modern techniques are not capable to completely overcome the complex root canal anatomy neither provide a perfect seal. Therefore, the influence of both quality of root canal treatment and coronal restoration on the long-term success of endodontic treatment is still a current topic of investigation. ${ }^{[4,5,12,13,17]}$

Given the increased diagnostic capacity of CBCT, the aim of this retrospective study was to use this three-dimensional examination to evaluate the relationship of the quality of root canal obturation and coronal restoration on the periapical status of endodontically treated teeth, using a study design similar to the one described by Ray and Trope in 1995. ${ }^{[1]}$

\section{MATERIALS AND METHODS}

Images were obtained from the records of patients visited for implant placement and/or surgical therapies and consequently were scanned with $\mathrm{CBCT}$ prior to any treatment. Ethical Committee protocol number was 528/17 and informed consent was obtained from all the individual participants included in the study. A total of 232 patients were randomly selected (age range between 25 and 65 years), who had not received any dental treatment in the 2 years prior to the $\mathrm{CBCT}$ examination.

The CBCT images were taken by using the Gendex GXDP-500 (Gendex Dental, Biberach, Germany), operated at $90 \mathrm{kVp}$ and $7 \mathrm{~mA}$, with exposure time of $23 \mathrm{~s}$ and a voxel size of $0.2 \mathrm{~mm}$, with a field of view of $13 \mathrm{~cm} \times 13 \mathrm{~cm}$. A total of 1011 endodontically treated teeth were selected for this research. The main inclusion criterion was the presence of previous endodontic treatment, i.e., radiopaque material placed inside the root canal space. However, the teeth restored with posts and/or presented large metal restorations or metallic crowns were excluded, to prevent biased analyses from scattering and beam hardening.

Before the evaluation and scoring, an oral radiologist and an endodontist were calibrated based on the criteria and variables established. The calibration included reviewing a random set of 100 images of endodontically treated teethin aPowerPoint(Microsoft, Redmond,WA) presentation. ${ }^{[4]}$ Inter-examinators' agreement during the calibration resulted in a high kappa score (0.81). The CBCT scans were evaluated in a room with a dimmed light, simultaneously by the two reviewers to reach a consensus for the interpretation. The images were examined by using specific software (i-CAT Vision, Imaging Sciences International, Hatfield, PA) in a personal computer running under Microsoft Windows XP Professional (Microsoft Corp, Redmond, WA). The monitor used to view the images was a 22 " flat screen with a resolution of $1680 \times 1050$ pixels. The raters were allowed to adjust brightness, contrast, and zoom. For the evaluation of the quality of restorations, a panoramic image perpendicular to the dental arch was created by using a curved MPR.

The quality of their endodontic obturation and coronal restoration was categorized as follows:

1. Good endodontic filling (GE): All the canals were obturated, with no visible voids, and apical limit of the obturation was in the $0-2 \mathrm{~mm}$ range short to the apex [Figure 1a-c] 

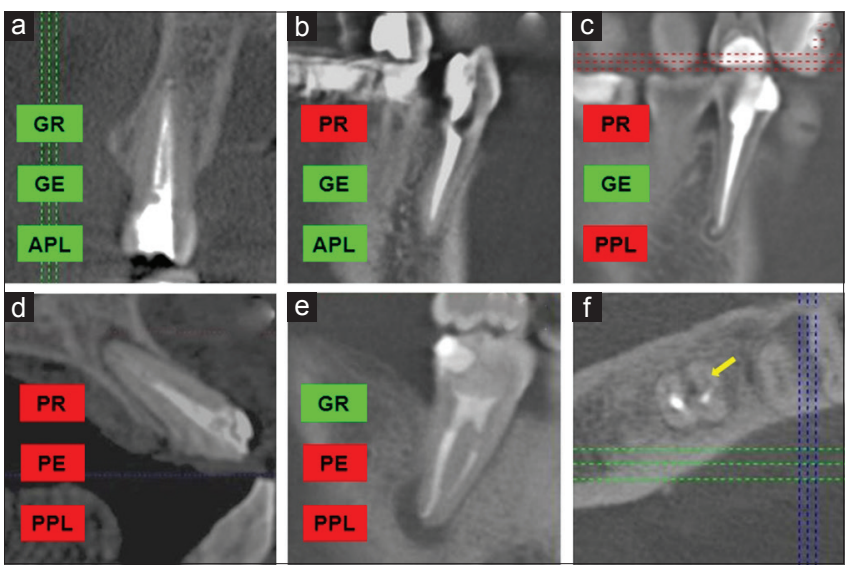

Figure 1: Cone-beam computed tomography images of endodontically treated teeth with different combinations of treatment quality and periapical status (a-e). GE $=$ Good endodontic, $\mathrm{PE}=$ Poor endodontic, $\mathrm{GR}=$ Good restoration, $\mathrm{PR}=$ Poor restoration, $\mathrm{APL}=$ Absence of periapical lesion, $\mathrm{PPL}=$ Presence of periapical lesion. Bicuspid with GE and GR presents no PPL (a). Cuspid presenting GE but PR is showing no PPL (b). A bicuspid with GE and PR showing PPL (c). An incisor with PE and PR is associated with PPL (d). An inferior molar presenting PPL (e) is associated with GR, but the cone-beam computed tomography axial scan revealed a missed mesiobuccal canal (f).

2. Poor endodontic filling (PE): One or more of the above-stated criteria ${ }^{[1]}$ were not met [Figure $1 d$, e and $\mathrm{f}$ ]

3. Good restoration (GR): Any permanent restoration that appeared to have an adequate radiographic marginal seal [Figure 1a and e]

4. Poor restoration (PR): Teeth without a restoration, or presenting any restoration that did not meet the above criteria ${ }^{[3]}$ or presented signs of open margins and/or over- or under-filled restorations [Figure $1 b$ and c].

The CBCT apical health status of apical one-third and surrounding structures was evaluated by a modified CBCT periapical index (CBCTPAI score). ${ }^{[27]}$ The CBCTPAI consists of an ordinal 6-point (0-5) scale ranging from no disease to severe periodontitis with two additional variables, expansion bone and destruction of cortical bone. The CBCTPAI score is given by the largest extension of the lesion, measured in three dimensions (buccopalatal, mesiodistal, and diagonal). In the present research, aiming to establish a comparison with Ray and Trope's study, the CBCTPAI score was adapted as follows:

- Absence of periapical lesion (APL): CBCTPAI 0 (intact periapical bone structures) presenting the contour, width, and structure of the periodontal ligament normal or slightly widened $(\leq 0.5 \mathrm{~mm})$ if an excess of filling material was present [Figure $1 \mathrm{a}$ and $\mathrm{b}$ ]

- Presence of periapical lesion (PPL): presence of periapical radiolucency with the diameter $>0.5 \mathrm{~mm}$ (CBCTPAI 1 or greater) [Figure 1c-e].

The multirooted teeth were ranked according to the root with the worst score. Data were statistically analyzed to correlate the periapical status with gender, dental group, and quality of endodontic treatment and restoration (Chi-square test with a significance level of $P<0.001$ ). The combinations of treatment quality were contrasted with their respective percentages of APL and PPL outcome ( $Z$ proportions' test). The logistic regression models were estimated for each of the variables to determine the odds ratios (ORs) of PPL outcome (significance level of $P<0.05$ ).

\section{RESULTS}

The results showed that 555 teeth $(54.9 \%)$ met the success criteria of APL, while $45.1 \%(n=456)$ of endodontically treated teeth presented PPL on CBCT. Table 1 presents the periapical status according to gender, dental group, and quality of endodontic treatment and restoration. The periapical outcome was not related to gender or dental group $(P>0.05)$. The good quality of both endodontic treatment and restoration significantly presented more APL $(P<0.0001)$. The odds of PPL outcome was 2.01 (95\% confidence interval [CI]: 1.52-2.66) times greater for the PE compared to GE, while it was 1.84 (95\% CI: 1.43-2.36) times greater for the PR compared to GR.

The different combinations of treatment quality were found to be a statistically significant factor (Chi-square test, $P<0.0001$ ). Table 2 presents the outcomes of the periradicular status according to the combinations of treatment for all teeth, also when separated into anterior and posterior. The combination of GE/GR resulted in the greatest APL outcome, followed by GE/PR. The teeth with PE/GR presented with significantly more PPL compared to GE/GR and lower than PE/PR. The PE/PR teeth resulted in the worst outcome, with statistically more PPL than APL, and the OR shows that it is 3.3 times more probable to present PPL compared to GE/GR.

For the anterior teeth, the combinations of GE/PR and PE/GR GE/GR were intermediate but not significantly different from the higher APL outcome (GE/GR) or the lower (PE/PR). For the posterior teeth, the teeth with both PE/GR and PE/PR presented significantly less APL than GE/GR. The OR showed that for the anterior teeth, the PE/PR combination is 2.7 times 
Gambarini, et al.: Cone-beam CT in the assessment of periapical lesions

\begin{tabular}{|c|c|c|c|c|c|}
\hline & $n$ & PPL, $n(\%)$ & APL, $n(\%)$ & $P^{*}$ & OR (95\% ICW) \\
\hline \multicolumn{6}{|l|}{ Gender } \\
\hline Female & 480 & $232(43.05)$ & $248(56.95)$ & 0.159 & 1.00 (reference) \\
\hline Male & 531 & $224(47.45)$ & $307(52.55)$ & & $1.19(0.93-1.53)$ \\
\hline \multicolumn{6}{|l|}{ Dental group } \\
\hline Maxillary anterior & 154 & $71(46.10)$ & $83(53.90)$ & 0.926 & 1.00 (reference) \\
\hline Mandibular anterior & 55 & $24(43.63)$ & $31(56.37)$ & & $0.90(0.49-1.68)$ \\
\hline Maxillary bicuspid & 218 & $93(42.66)$ & $125(57.34)$ & & $0.87(0.57-1.31)$ \\
\hline Mandibular bicuspid & 136 & $59(43.38)$ & $77(56.62)$ & & $0.89(0.56-1.42)$ \\
\hline Maxillary molar & 225 & $107(47.56)$ & $118(52.44)$ & & $1.06(0.70-1.59)$ \\
\hline Mandibular molar & 223 & $102(45.73)$ & $121(54.27)$ & & $0.98(0.65-1.49)$ \\
\hline \multicolumn{6}{|l|}{ Endodontic treatment } \\
\hline Good (GE) & 311 & $104(33.44)$ & $207(66.56)$ & $<0.0001$ & 1.00 (reference) \\
\hline Poor (PE) & 700 & $352(50.28)$ & $348(49.72)$ & & $2.01(1.52-2.66)$ \\
\hline \multicolumn{6}{|l|}{ Coronal restoration } \\
\hline Good (GR) & 564 & $217(38.48)$ & $347(61.52)$ & $<0.0001$ & 1.00 (reference) \\
\hline Poor (PR) & 447 & $239(53.47)$ & $208(46.53)$ & & $1.84(1.43-2.36)$ \\
\hline
\end{tabular}

\begin{tabular}{|c|c|c|c|c|c|}
\hline & Coronal restoration & $n$ & PPL, $n(\%)$ & APL, $n(\%)$ & OR (95\% ICW) \\
\hline \multicolumn{6}{|c|}{ Endodontic treatment } \\
\hline Good (GE) & Good (GR) & 194 & $58(29.90)^{a, A}$ & $136(70.10)^{\mathrm{a}, \mathrm{B}}$ & 1.00 (reference) \\
\hline Good (GE) & Poor (PR) & 117 & $46(39.32)^{a, b, A}$ & $71(60.68)^{\mathrm{a}, \mathrm{b}, \mathrm{A}}$ & $1.52(0.93-2.46)$ \\
\hline Poor (PE) & Good (GR) & 370 & $159(42.97)^{\mathrm{b}, \mathrm{A}}$ & $211(57.03)^{\mathrm{b}, \mathrm{A}}$ & $1.76(1.22-2.56)$ \\
\hline Poor (PE) & Poor (PR) & 330 & $193(58.48)^{\mathrm{c}, \mathrm{A}}$ & $137(41.52)^{\mathrm{c}, \mathrm{B}}$ & $3.30(2.26-4.81)$ \\
\hline Total & & 1011 & $456(45.10)$ & $555(54.90)$ & \\
\hline \multicolumn{6}{|l|}{ Anterior } \\
\hline Good (GE) & Good (GR) & 74 & $25(33.78)^{\mathrm{a}, \mathrm{A}}$ & $49(66.22)^{\mathrm{a}, \mathrm{B}}$ & 1.00 (reference) \\
\hline Good (GE) & Poor (PR) & 22 & $11(50.00)^{a, b, A}$ & $11(50.00)^{\mathrm{a}, \mathrm{b}, \mathrm{A}}$ & $1.96(0.75-5.14)$ \\
\hline Poor (PE) & Good (GR) & 68 & $33(48.53)^{\mathrm{a}, \mathrm{b}, \mathrm{A}}$ & $35(51.47)^{\mathrm{a}, \mathrm{b}, \mathrm{A}}$ & $1.85(0.94-3.64)$ \\
\hline Poor (PE) & Poor (PR) & 45 & $26(57.78)^{\mathrm{b}, \mathrm{A}}$ & $19(42.22)^{\mathrm{b}, \mathrm{A}}$ & $2.68(1.25-5.75)$ \\
\hline Total & & 209 & $95(45.45)$ & $114(54.55)$ & \\
\hline \multicolumn{6}{|l|}{ Posterior } \\
\hline Good (GE) & Good (GR) & 120 & $33(27.50)^{\mathrm{a}, \mathrm{A}}$ & $87(72.50)^{a, B}$ & 1.00 (reference) \\
\hline Good (GE) & Poor (PR) & 95 & $35(36.84)^{a, b, A}$ & $60(63.16)^{\mathrm{a}, \mathrm{b}, \mathrm{A}}$ & $1.53(0.86-2.74)$ \\
\hline Poor (PE) & Good (GR) & 302 & $126(41.72)^{\mathrm{b}, \mathrm{A}}$ & $176(58.28)^{\mathrm{b}, \mathrm{A}}$ & $1.89(1.19-2.99)$ \\
\hline Poor (PE) & Poor (PR) & 285 & $167(58.60)^{\mathrm{c}, \mathrm{A}}$ & $118(41.40)^{\mathrm{C}, \mathrm{B}}$ & $3.73(2.34-5.94)$ \\
\hline Total & & 802 & $361(45.01)$ & 441 (54.99) & \\
\hline
\end{tabular}

more probable to present PPL while for posterior teeth the OR is 3.7.

\section{DISCUSSION}

One of the fundamental assumptions of scientific studies is the reproducibility, in order to allow the confirmation or refusal of previous findings. The 1995' Ray and Trope's cross-sectional study ${ }^{[1]}$ has been reproduced by different research groups and in different populations, as shown in Table 3.
Unfortunately, regardless of the geographic location and some differences in the methodology, most of these epidemiological studies presented high rates of inadequate root fillings and a prevalence of periapical radiolucencies varying from $32.5 \%$ to $67 \% \cdot{ }^{[4,7,9-11,13,15]} \mathrm{In}$ the present study, the overall prevalence of lesions in endodontically treated teeth was $45.1 \%$, which is within the range reported in the literature.

Differently, cohort studies with controlled clinical environments and standardized techniques have 
Gambarini, et al.: Cone-beam CT in the assessment of periapical lesions

\begin{tabular}{|c|c|c|c|c|c|c|c|c|c|c|c|}
\hline \multirow[t]{2}{*}{ Years } & \multirow[t]{2}{*}{ Authors } & \multirow[t]{2}{*}{ Country } & \multirow[t]{2}{*}{ Evaluation } & \multirow[t]{2}{*}{$n$} & \multirow[t]{2}{*}{ GE (\%) } & \multirow[t]{2}{*}{ GR (\%) } & \multicolumn{5}{|c|}{ Success rate (APL) } \\
\hline & & & & & & & Overall (\%) & GE/GR (\%) & GE/PR (\%) & PE/GR (\%) & PE/PR (\%) \\
\hline 1995 & Ray and Trope & $\begin{array}{l}\text { The United } \\
\text { States }\end{array}$ & $\mathrm{RX}$ & 985 & 50.2 & 64.2 & 61.07 & 91.4 & 44.1 & 67.6 & 18.1 \\
\hline 2000 & Tronstad et al. & Norway & $\mathrm{RX}$ & 1001 & 50.5 & 66.2 & 67.4 & 80.8 & 71.1 & 56.2 & 57 \\
\hline 2002 & Hommez et al. & Belgium & RX/clinical & 745 & 34.3 & 67.4 & 67.5 & 79.3 & 65.9 & 68.1 & 56.8 \\
\hline 2003 & Dugas et al. & Canada & RX/clinical & 383 & 38.9 & 42.3 & 54.56 & 81.4 & 60.8 & 46.7 & 43 \\
\hline 2004 & Segura-Egea et al. & Spain & $\mathrm{RX}$ & 93 & 34.4 & 35.48 & 35.5 & 68.8 & 37.5 & 29.4 & 25 \\
\hline 2005 & Siqueira et al. & Brazil & $\mathrm{RX}$ & 2051 & 56.9 & 46.7 & 49.7 & 71.1 & 65.3 & 37.9 & 18 \\
\hline 2008 & Georgopoulou et al. & Greece & $\mathrm{RX}$ & $1120^{*}$ & 42.5 & 45.5 & 45 & 60.8 & 32.9 & 43.9 & 32.4 \\
\hline 2009 & Tavares et al. & France & $\mathrm{RX}$ & 1035 & 19.13 & 64.54 & 67 & 93.5 & 82.2 & 64.1 & 56 \\
\hline 2011 & Gunduz et al. & Turkey & $\mathrm{RX}$ & 1014 & 41.9 & 30.6 & 32.1 & 76.2 & 45 & 10.8 & 3.7 \\
\hline 2013 & Kalender et al. & Cyprus & $\mathrm{RX}$ & 2200 & 38.2 & $93^{*}$ & 38 & 77.2 & 64.7 & 23.1 & 5.2 \\
\hline 2013 & Moreno et al. & Columbia & $\mathrm{RX}$ & 1086 & 33.2 & 39.9 & 51 & 66 & 56 & 52 & 43 \\
\hline 2014 & Song et al. & South Korea & $\mathrm{RX} /$ clinical & 1030 & 35.6 & 68.6 & 59.1 & 82.3 & 56.3 & 54.7 & 41.2 \\
\hline 2015 & Gomes et al. & Brazil & СВСТ & 1290 & 55.12 & $94.73^{\star *}$ & 48.83 & 59.44 & 51.52 & 37.13 & 22.85 \\
\hline 2015 & Present study & Italy & СВCT & 1011 & 30.76 & 55.78 & 54.9 & 70.1 & 60.68 & 57.03 & 41.52 \\
\hline
\end{tabular}

shown higher success rates $(85 \%-90 \%) .{ }^{[16,30]}$ Indeed, a cross-sectional study design has some limitations because it provides information about a population at one point in time, and there are no information about how the root canal treatments were performed. Of the four factors influencing the outcome of root canal treatment identified in a systematic review, ${ }^{[3]}$ three can be assessed in a transversal study: the quality of coronal restoration, the density of the obturation, and its apical extent; the only lacking factor is the preoperative apical status. Since there are no available information about the pathological history and systemic conditions of the patients, it is not possible to determine whether if the apical lesion is healing or progressing. However, in the present study, only patients who reported to have not received any dental treatment in the last 2 years before the CBCT scans were selected. This is a consistent period of time in order to detect apical alterations after an endodontic treatment. ${ }^{[22,31]}$ Moreover, the substantial number of randomly selected patients/teeth compensates the misdiagnoses that might occur in a cross-sectional study, validating the meaning of the results. ${ }^{[32]}$

The present study design was as similar as practically possible to Ray and Trope's, ${ }^{[1]}$ the same amount of randomly selected teeth was evaluated, with similar selection and evaluation criteria. However, more than replicating a study, it is important to detect the relevant parameters that might influence the experimental protocol. In this sense, there are three main differences between the 1995's and the present study: (1) the use of $\mathrm{CBCT}$, aiming at more accurate diagnosis of the periapical status; (2) the comparison among dental groups; and (3) the technical improvements that occurred in dentistry in these two decades.

Compared to Ray and Trope, ${ }^{[1]}$ we found more deviations in our study leading to categorizing unsatisfactory treatments and more periapical lesion diagnosis. The percentage of GE, GR, and overall success rate was lower, as well as the APL percentage in GE/GR, GE/PR, and PE/GR [Table 3]. Our study diagnosed higher number of PPL 456 versus 372, 5 from Ray and Trope (45.1\% vs. 38.93\%, respectively), and our number of PE/PR is almost doubled (330 vs. 188, respectively, $41.52 \%$ vs. $18.1 \%$ ). This higher prevalence of PPL was expected due to the use of CBCT, confirming previous studies that reported the better accuracy in the detection of apical alterations compared to two-dimensional analog radiography. ${ }^{[22-24]}$

The main disadvantage of periapical radiography is the superimposition of structures in multiple planes, which leads to more false-negative results. ${ }^{[21]}$ The CBCT can almost double the capacity to diagnose periapical lesions after endodontic treatment compared to a two-dimensional analog X-ray and also allow the earlier detection of small periapical alterations. ${ }^{[18,21,31]}$ In a clinical study that compared the alterations in the periapical status 1 year after endodontic treatment of 123 teeth, 14 times more PPLs were detected with $\mathrm{CBCT}$ when compared to radiographs. ${ }^{[22]}$ Moreover, different from radiographic studies, in the present research, it was possible to precisely measure the PPL 
extension, increasing the reliability of the data. ${ }^{[27]} \mathrm{In}$ this perspective, when comparing our results with Ray and Trope's, ${ }^{[1]}$ the shift in success rate from $61.07 \%$ (1995) to the present $54.9 \%$ is lesser than expected. We consider our findings as a result of endodontic improvement in the last two decades. Similarly, recent CBCT studies reported an overall absence of lesions in $48.83 \%{ }^{[4]}$ and $54.4 \% .{ }^{[17]}$

The quality of root filling has been categorized in the literature with different methodologies. However, not only the length of the obturation but also the lateral seal (absence of voids) has been correlated with the periapical status. ${ }^{[33]}$ Regarding the overall quality of treatment, our percentage of GE and GR was lower than that of most of the previous studies [Table 3]. This is mainly explained by the increased capacity of CBCT to detect voids and precisely define the apical extent of root canal fillings. ${ }^{[26,31]}$ While the periapical radiographs can only provide the mesiodistal aspect, thus underestimating the presence of voids, ${ }^{[34]}$ the CBCT might lead to an overestimation. ${ }^{[35]}$ Liang et al. ${ }^{[31]}$ showed that approximately $10 \%$ of filling with adequate length in the $X$-rays appeared too long in the $\mathrm{CBCT}$ and also that the detection of voids was three times greater with the three-dimensional examination.

In accordance with most of the previous studies, the present success rate of endodontic treatment was positively correlated with the good technical quality of the root filling. ${ }^{[2,9-14,33]}$ However, differently as stated by Ray and Trope, ${ }^{[1]}$ in the present study, the endodontic obturation had a slightly higher impact than restoration in the long-term success of the endodontic treatment. Results from the present study are similar to Hommez et al. ${ }^{[7]}$ which reported that the periapical status was not significantly influenced by the quality of restoration when combined with a GE. Some researchers also showed that endodontic quality had significantly higher impact on the outcome of endodontic treatments. ${ }^{[9,10,14]}$

The present study results showed odds of PPL outcome 1.84 greater when a PR was present, while Ray and Trope reported OR of 11.12 (95\% CI: 8-15.47). Recently, Gomes et al. ${ }^{[4]}$ using CBCT reported only a 0.6 times OR for a healthy periapical condition with the presence of coronal restoration when compared with its absence. These authors did not report the quality of restorations due to impossibility of elimination of artifacts, which means that good and badly adapted restorations were categorized as the same. In fact, the CBCT evaluation of both coronal restorations and endodontic fillings might be complicated due to scattered X-ray artifacts. ${ }^{[36]}$ The CBCT has been reported in the evaluation of the quality of restorations and detection of caries. ${ }^{[17,37,38]}$ In the present study, the cases that presented images with scattered artifacts were excluded (e.g., metallic posts and large metal restorations) and the criteria for the quality of restorations were limited to its marginal sealing, which is similar to an evaluation of a standard radiographic examination. Even though, as many other previous studies evaluate only images (X-rays or CBCT), the lack of clinical evaluation could be itself a potential bias. ${ }^{[38]}$

The anatomic complexities of the root canal system are more frequently found in bicuspids and molars. ${ }^{[39]}$ Some previous studies have demonstrated the correlation between posterior endodontically treated teeth with PPL. ${ }^{[2,4]}$ Although in the Ray and Trope' $\mathrm{s}^{[1]}$ study the difference among dental groups was not described, in the present study, this factor was also investigated. Results showed that the anatomic group was not a significant factor with the presence of PPL [Table 1]. However, since a larger number of posterior teeth were evaluated (802 vs. only 209 anterior), the statistical analysis was also performed for these distinct groups regarding the different combinations of treatment quality [Table 2]. The results showed that for posterior teeth, the PE/GR presented a significantly higher percentage of PPL compared to GE/GR and lesser than PE/PR. For anterior teeth, excluding the GE/GR combination, there were no relevant differences among the other combinations of treatment quality. This means that the quality of restoration was slightly more relevant for the posterior teeth. Furthermore, for the combination of PE/PR, the odds of presenting PPL was 3.7 for posterior teeth, while for anterior, it was 2.7 times greater when compared to GE/GR.

A 10-year radiographic follow-up study by Kirkevang et al. ${ }^{[40]}$ showed that PE primarily affected the risk of PPL and, to a smaller extent, the risk of extraction, whereas a PR primarily affected the risk of extraction and, to a smaller extent, the PPL. Our results showed that the quality of endodontic treatment was slightly more relevant than restoration in the APL outcome; the PR teeth presented significantly more PPL than teeth with GR, which means that clinically both quality of restoration and obturation are relevant to obtain endodontic success. This is in agreement with different previous researches and one meta-analysis which addressed no significant differences in the odds of healing between GE/PR and PE/GR. ${ }^{[4-7]}$ 
Finally, the criteria used by Ray and Trope ${ }^{[1]}$ defining the presence of radiolucencies as inflammation, are not appropriate because sometimes healing may result in fibrous scar tissue, which is radiographically indistinguishable from an apical granuloma. ${ }^{[41]}$ However, there is no available imaging examination to determine the histological content of a radiographic apical lesion; therefore, the PPL is still currently related to clinical failure. Although the CBCT is a reliable tool for the diagnosis of periapical status, the long-term success of endodontically treated teeth might consider not only the absence of periapical lesions, but also the criteria of a functional and asymptomatic tooth. Future researches should combine clinical evaluation of coronal restoration integrity and CBCT monitoring of the apical status, for a more complete understanding of endodontic outcomes.

\section{CONCLUSIONS}

Congruent with Ray and Trope, ${ }^{[1]}$ results of the present study confirm that the combination of both high-quality endodontic obturation and coronal restoration increases the success of endodontically treated teeth. However, the coronal restoration quality had a lesser impact on endodontic treatment outcome than the root canal obturation.

\section{Financial support and sponsorship Nil.}

\section{Conflicts of interest}

There are no conflicts of interest.

\section{REFERENCES}

1. Ray HA, Trope M. Periapical status of endodontically treated teeth in relation to the technical quality of the root filling and the coronal restoration. Int Endod J 1995;28:12-8.

2. Sjogren U, Hagglund B, Sundqvist G, Wing K. Factors affecting the long-term results of endodontic treatment. J Endod 1990;16:498-504.

3. Ng YL, Mann V, Rahbaran S, Lewsey J, Gulabivala K. Outcome of primary root canal treatment: Systematic review of the literature-Part 1. Effects of study characteristics on probability of success. Int Endod J 2007;40:921-39.

4. Gomes AC, Nejaim Y, Silva AI, Haiter-Neto F, Cohenca N, Zaia AA, et al. Influence of endodontic treatment and coronal restoration on status of periapical tissues: A cone-beam computed tomographic study. J Endod 2007;41:1614-8.

5. Song M, Park M, Lee CY, Kim E. Periapical status related to the quality of coronal restorations and root fillings in a Korean population. J Endod 2014;40:182-86.

6. Gillen BM, Looney SW, Gu LS, Loushine BA, Weller RN, Loushine RJ, et al. Impact of the quality of coronal restoration versus the quality of root canal fillings on success of root canal treatment: A systematic review and meta-analysis. J Endod 2011;37:895-902.

7. Hommez GM, Coppens CR, De Moor RJ. Periapical health related to the quality of coronal restorations and root fillings. Int Endod J 2002;35:680-9.

8. Georgopoulou MK, Spanaki-Voreadi AP, Pantazis N, Kontakiotis EG,
Morfis AS. Periapical status and quality of root canal fillings and coronal restorations in a Greek population. Quintessence Int 2008;39:e85-92.

9. Dugas NN, Lawrence HP, Teplitsky PE, Pharoah MJ, Friedman S. Periapical health and treatment quality assessment of root-filled teeth in two Canadian populations. Int Endod J 2003;36:181-92.

10. Segura-Egea JJ, Jiménez-Pinzón A, Poyato-Ferrera M, Velasco-Ortega E, Ríos-Santos JV. Periapical status and quality of root fillings and coronal restorations in an adult Spanish population. Int Endod J 2004;37:525-30.

11. Tavares PB, Bonte E, Boukpessi T, Siqueira JF Jr., Lasfargues JJ. Prevalence of apical periodontitis in root canal-treated teeth from an urban French population: Influence of the quality of root canal fillings and coronal restorations. J Endod 2009;35:810-3.

12. Kalender A, Orhan K, Aksoy U, Basmaci F, Er F, Alankus A, et al. Influence of the quality of endodontic treatment and coronal restorations on the prevalence of apical periodontitis in a Turkish Cypriot population. Med Princ Pract 2013;22:173-7.

13. Moreno JO, Alves FR, Gonçalves LS, Martinez AM, Rôças IN, Siqueira JF Jr. Periradicular status and quality of root canal fillings and coronal restorations in an urban Colombian population. J Endod 2013;39:600-4.

14. Tronstad L, Asbjørnsen K, Døving L, Pedersen I, Eriksen HM. Influence of coronal restorations on the periapical health of endodontically treated teeth. Endod Dent Traumatol 2000;16:218-21.

15. Gündüz K, Avsever H, Orhan K, Demirkaya K. Cross-sectional evaluation of the periapical status as related to quality of root canal fillings and coronal restorations in a rural adult male population of turkey. BMC Oral Health 2011;11:20.

16. Craveiro MA, Fontana CE, Martin AS, Bueno CE. Influence of coronal restoration and root canal filling quality on periapical status: Clinical and radiographic evaluation. J Endod 2015;41:836-40.

17. Nur BG, Ok E, Altunsoy M, Aglarci OS, Çolak M, Güngör E. Evaluation of technical quality and periapical health of root-filled teeth by using cone-beam CT. J Appl Oral Sci 2014;22:502-8.

18. Estrela C, Bueno MR, Leles CR, Azevedo B, Azevedo JR. Accuracy of cone beam computed tomography and panoramic and periapical radiography for detection of apical periodontitis. J Endod 2008;34:273-9.

19. Cotton TP, Geisler TM, Holden DT, Schwartz SA, Schindler WG. Endodontic applications of cone-beam volumetric tomography. J Endod 2007;33:1121-32.

20. Low KM, Dula K, Bürgin W, von Arx T. Comparison of periapical radiography and limited cone-beam tomography in posterior maxillary teeth referred for apical surgery. J Endod 2008;34:557-62.

21. Tsai P, Torabinejad M, Rice D, Azevedo B. Accuracy of cone-beam computed tomography and periapical radiography in detecting small periapical lesions. J Endod 2012;38:965-70.

22. Patel S, Wilson R, Dawood A, Foschi F, Mannocci F. The detection of periapical pathosis using digital periapical radiography and cone beam computed tomography-part 2: A 1-year post-treatment follow-up. Int Endod J 2012;45:711-23.

23. Lofthag-Hansen S, Huumonen S, Gröndahl K, Gröndahl HG. Limited cone-beam CT and intraoral radiography for the diagnosis of periapical pathology. Oral Surg Oral Med Oral Pathol Oral Radiol Endod 2007;103:114-9.

24. de Paula-Silva FW, Wu MK, Leonardo MR, da Silva LA, Wesselink PR. Accuracy of periapical radiography and cone-beam computed tomography scans in diagnosing apical periodontitis using histopathological findings as a gold standard. J Endod 2009;35:1009-12.

25. Patel S, Dawood A, Mannocci F, Wilson R, Pitt Ford T. Detection of periapical bone defects in human jaws using cone beam computed tomography and intraoral radiography. Int Endod J 2009;42:507-15.

26. Venskutonis T, Plotino G, Juodzbalys G, Mickevičienė L. The importance of cone-beam computed tomography in the management of endodontic problems: A review of the literature. J Endod 2014;40:1895-901.

27. Estrela C, Bueno MR, Azevedo BC, Azevedo JR, Pécora JD. A new periapical index based on cone beam computed tomography. J Endod 2008;34:1352-31.

28. Peters CI, Peters OA. Cone beam computed tomography and other imaging techniques in the determination of periapical healing. Endodontic Topics 2012;10:57-75.

29. Ørstavik D, Pitt Ford TR. Apical periodontitis: Microbial infection and host responses. In: Ørstavik D, Pitt Ford TR, editors. Essential 
Endodontology. Vol. 1. Oxford: Blackwell Science; 1998. p. 8-9.

30. Ricucci D, Russo J, Rutberg M, Burleson JA, Spångberg LS. A prospect cohort study of endodontic treatments of 1369 root canals: Results after 5 years. Oral Surg Oral Med Oral Pathol Oral Radiol Endod 2011;112:825-42.

31. Liang YH, Li G, Wesselink PR, Wu MK. Endodontic outcome predictors identified with periapical radiographs and cone-beam computed tomography scans. J Endod 2011;37:326-31.

32. Altman DG. Practical Statistics for Medical Research. London: Chapman \& Hall; 1991.

33. Kirkevang LL, Ørstavik D, Hörsted-Bindslev P, Wenzel A. Periapical status and quality of root fillings and coronal restorations in a Danish population. Int Endod J 2000;33:509-15.

34. Eckerbom M, Magnusson T. Evaluation of technical quality of endodontic treatment-reliability of intraoral radiographs. Endod Dent Traumatol 1997;13:259-64.

35. Møller L, Wenzel A, Wegge-Larsen AM, Ding M, Væth M, Hirsch E, et al. Comparison of images from digital intraoral receptors and cone beam computed tomography scanning for detection of voids in root canal fillings: An in vitro study using micro-computed tomography as validation. Oral Surg Oral Med Oral Pathol Oral
Radiol 2013;115:810-8.

36. Weber MT, Stratz N, Fleiner J, Schulze D, Hannig C. Possibilities and limits of imaging endodontic structures with CBCT. Swiss Dent J 2015;125:293-311

37. Sansare K, Singh D, Sontakke S, Karjodkar F, Saxena V, Frydenberg M, et al. Should cavitation in proximal surfaces be reported in cone beam computed tomography examination? Caries Res 2014;48:208-13.

38. Ozturk E, Sinanoglu A. Histological validation of cone-beam computed tomography versus laser fluorescence and conventional diagnostic methods for occlusal caries detection. Photomed Laser Surg 2015;33:61-8.

39. Vertucci FJ. Root canal morphology and its relationship to endodontic procedures. Endod Top 2005;10:3-29.

40. Kirkevang LL, Vaeth M, Wenzel A. Ten-year follow-up of root filled teeth: A radiographic study of a Danish population. Int Endod J 2014;47:980-8.

41. Nair PN, Sjögren U, Figdor D, Sundqvist G. Persistent periapical radiolucencies of root-filled human teeth, failed endodontic treatments, and periapical scars. Oral Surg Oral Med Oral Pathol Oral Radiol Endod 1999;87:617-27. 